\title{
Effect of Impact Modifiers on Strength and Fracture Toughness of CFRPs
}

\author{
Dionisis Semitekolos ${ }^{1}$, Ioannis G. Asimakopoulos ${ }^{1}$, Dimitrios A. Dragatogiannis ${ }^{1}$ and \\ Costas A. Charitidis ${ }^{1}$ \\ ${ }^{1}$ National Technical University of Athens, Department of Chemical Engineering, RNANO \\ Lab - Research Unit of Advanced, Composite, Nanomaterials and Nanotechnology, 9 \\ Heroon Polytechneiou st., Zografos Athens, GR-15773
}

\begin{abstract}
The aim of this work is to study the effect of core-shell rubbers on the mechanical properties of CFRPs.For the preparation of composites, two types of resins were used, a three-component Araldite resin (resin-hardener-accelerator system in proportions of 100-900,5 by weight respectively), and MX 156, which contains $25 \%$ core-shell elastomers and 75 $\%$ Araldite resin. Depending on the mechanical test, two types of carbon fibre fabrics (UD C415, G0926) are used with corresponding number of layers. The composites were prepared by vacuum infusion and cut to the appropriate dimensions by water-cutting. They were tested for mechanical performance, by bending, shearing, tensile, impact and fracture toughness tests, to compare the properties of CSR-containing composites and reference CFRPs. Fracture analysis of specimens was performed by scanning electron microscopy (SEM). The results exhibited a $50 \%$ increase in impact strength while the energy absorbed during the fracture toughness test was 4 times greater on specimens with CSR than reference.
\end{abstract}

\section{Introduction}

Carbon fibre-reinforced composites are widely used in many industries, such as aerospace and automotive. The widespread use of these materials is due to their very good mechanical properties, high elasticity and low density [1]. The fact that the fibres are not chemically bonded to the epoxy matrix, in combination with the cross-linked structure of epoxy polymers makes these composite materials sensitive to the propagation of cracks and weak impact resistance. This phenomenon affects the mechanical performance of materials [2].

The introduction of the core-shell rubbers (CSR) in the fibre-matrix composite can absorb a larger quantity of energy and thus extend the life of the materials and their strength. The impact strength of the composites after the addition of CSR is improved through their ability to absorb the vibrations of the composites and terminate the propagation of cracks [3]. Despite the improved performance on fracture, this addition can negatively affect Young's modulus of the cured epoxy polymer, increase the viscosity of the resin or even decrease the glass transition temperature, resulting in harder processability and application of these composites.

Silica nanoparticle is a common rigid filler that is used to increase the stiffness and fracture energy of CFRPs without influencing the kinetic properties of the resin, however, the increase in fracture energy is relatively smaller compared to rubber particles. As advantage silica nanoparticles are not filtered during infusion and have a small effect on the viscosity that can reach $20 \%$ [4].

Liquid reactive rubbers are normally used to improve the toughness of epoxies such as carboxyl-terminated butadiene acrylonitrile (CTBN). These particles that initially are soluble in the uncured resin, separate during the curing to form rubbery particles[5]. However, such systems exhibit significant drawbacks when used with fast cure epoxy resins, due to insufficient/incomplete rubber domain formation and differences in the microstructure between the centre and surface of the fibre composite plates[6]. 
These drawbacks can be overcome with the use of preformed core-shell rubber particles. The size of these particles can be adjusted from their formulation due to emulsion polymerisation. Recent advances have proved that these particles exhibit good dispersion in the epoxy matrices, increase fracture properties while maintaining glass transition temperature and viscosity [7]. This study aims to investigate the effect of core-shell rubbers on the mechanical properties of CFRPs.

\section{Experimental}

\subsection{Materials and Methods}

As for the carbon fibres, they are taken in the form of fabric and depending on the mechanical test of the composite, two types of fabric are used. One type of fabric is G0926 from Hexcel Industries Inc., USA. The weave of the fabrics is $0-90^{\circ}$, where at $0^{\circ}$ there is carbon fibre (TENAX E HTA40 E13 6K) and at 90', glass fibre (EC9 34 Z40 1383). The nominal weight is $375 \mathrm{~g} / \mathrm{m}^{2}$ and its weight is due almost exclusively $(97 \%)$ to carbon fibre. The second type of fabric is from the company FIBERMAX composites, and their code is C415. The nominal weight is $415 \mathrm{~g} / \mathrm{m}^{2}$. This fabric is unidirectional.

Regarding the epoxy resin used as a matrix in the formulation, we have two cases, as on the one hand a simple three-component resin was used, while on the other hand the resin was used, in which the CSR were pre-dispersed. The three-component resin consists of Araldite LY 556, Aradur 917 hardener and DY 070 accelerator from HUNTSMAN industries (USA). The ratio of these three components of the resin is 100-90-0.5 by weight respectively. The other resin used was a three-component resin with the difference that component A is Kaneace MX 156 (Kaneka, Belgium), which contains $75 \%$ resin and 25\% CSR. Both systems cure at $80^{\circ} \mathrm{C}$ for 4 hours, followed by post-curing at $120^{\circ} \mathrm{C}$ for another 4 hours.

\subsection{Composite Manufacturing}

The types of fabrics used are G0926 woven and UD-C415, with nominal weights of $375 \mathrm{~g} /$ $\mathrm{m}^{2}$ and $415 \mathrm{~g} / \mathrm{m}^{2}$ respectively. The rule of thumb states that each layer of fabric used contributes $0.375 \mathrm{~mm}$ (UDC415 fabric) and $0.415 \mathrm{~mm}$ (G0926 fabric) to the thickness of the final composite. The number of layers used in each case in the final composite is determined based on the nominal weights of the fabrics and the thickness of the final composite, based on the ASTM standard of each test and specifically dividing the thickness of the composite by the nominal weight of the fabric. Thus, for the bending test 8 layers of G0926 fabric are used, for the shear UDC415 12-layer fabric, for the tensile test G0926 8layer fabric, for the impact test UDC415 10 layers and 12 layers UDC415 for the fracture toughness test.

In MX 156 epoxy resin, the CSR are dispersed and are present in component A at a rate of $25 \%$. The core-shell particles remain completely dispersed in the resin under normal conditions throughout the formation and curing of the composite. This resin is completely free of ionic and organic impurities that can slow down the curing process. The composites were manufactured via vacuum infusion (also known as vacuum-assisted resin transfer moulding VA-RTM).

The calculation of the fibre content is performed separately for each type of composite panel that has been manufactured. Based on the number of layers of fabric, the type of fabric (G0926 or UDC415) and the epoxy resin used, a total of 6 different types of panels are produced, depending on the test standards to be submitted. Specifically, in the tensile and flexural tests, 8 layers of G0926 fabric are used, in the fracture toughness and shear tests of UDC415 12 layers and finally in the impact test UDC415 10-layer fabric. In all 
tests, to compare the results, specimens containing reference resin (pristine) are made, as well as specimens with MX 156.

The formula for calculating in each case the fibre content is as follows:

$$
V_{r}(\%)=\frac{A_{r} * N_{p} * 0.1}{\rho_{r} * h}(1)
$$

where,

$\mathrm{A}_{\mathrm{r}}$ : Nominal weight of the fabric $(\mathrm{g} / \mathrm{m} 2)$

$\mathrm{N}_{\mathrm{p}}$ : Number of layers in the composite

$\rho_{\mathrm{r}}$ : Density of the fabric $(\mathrm{g} / \mathrm{cm} 3)$

h: Sample thickness ( $\mathrm{mm})$

The specimens for bend and tensile test have an average thickness of $3.05 \mathrm{~mm}$, while the characteristics of the G0926 fabric used are nominal weight $375 \mathrm{~g} / \mathrm{m}^{2}$ and density $1.76 \mathrm{~g} /$ $\mathrm{cm}^{3}$. Thus, the fibre content of these composites is $55.89 \%$.

For shear tests and fracture toughness, as mentioned above, a 12-layer UD fabric was used. The nominal weight of its surface is $415 \mathrm{~g} / \mathrm{m}^{2}$, the specimens have an average thickness of $4.5 \mathrm{~mm}$, while the density of the fabric is $1.82 \mathrm{~g} / \mathrm{cm}^{3}$. Thus, the fibre content is $60.8 \%$.

Finally, for the impact test, the reinforcement consists of a 10-layer UDC415 fabric. As mentioned above, the nominal surface weight is $415 \mathrm{~g} / \mathrm{m}^{2}$ and the density is $1.82 \mathrm{~g} / \mathrm{cm}^{3}$, while the average thickness of the samples subjected to the impact test is $4 \mathrm{~mm}$. From the above formula, the fibre content of the specimens is $57 \%$.

The main characteristics of the panels that were constructed are summarized in the following table.

Table 1. Main characteristics of the manufactured CFRP panels

\begin{tabular}{|c|c|c|c|c|c|c|}
\hline $\mathbf{A} / \mathbf{A}$ & Matrix & $\begin{array}{c}\text { Matrix } \\
\text { Mixing } \\
\text { Ratio }\end{array}$ & $\begin{array}{l}\text { Fabric } \\
\text { Type }\end{array}$ & $\begin{array}{l}\text { Number } \\
\text { of plies }\end{array}$ & $V_{f}(\%)$ & $\begin{array}{c}\text { Mechanical } \\
\text { Tests }\end{array}$ \\
\hline $\begin{array}{c}\text { Pristi } \\
\text { ne_P } \\
\text { anel_ } \\
1\end{array}$ & \multirow{3}{*}{ 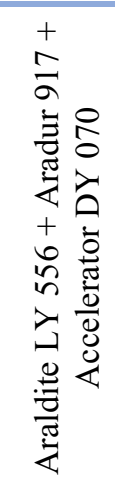 } & \multirow{3}{*}{ 100:90:0.5 } & G0926 & 8 & 55,89 & $\begin{array}{l}3 \text { point bend } \\
\text { Tensile }\end{array}$ \\
\hline $\begin{array}{l}\text { Pristi } \\
\text { ne_P } \\
\text { anel_ } \\
2\end{array}$ & & & UD C415 & 12 & 60,8 & $\begin{array}{c}\text { MODE I } \\
\text { Short beam }\end{array}$ \\
\hline $\begin{array}{c}\text { Pristi } \\
\text { ne_P } \\
\text { anel__ } \\
3\end{array}$ & & & UD C415 & 10 & 56,5 & Impact \\
\hline $\begin{array}{c}\text { MX1 } \\
\text { 56_P } \\
\text { anel_ } \\
1\end{array}$ & \multirow{2}{*}{ 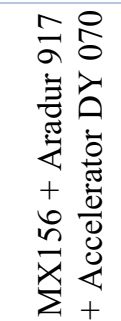 } & \multirow{2}{*}{$133: 90: 0.5$} & G0926 & 8 & 58,7 & $\begin{array}{l}\text { 3point bend } \\
\text { Tensile }\end{array}$ \\
\hline $\begin{array}{c}\text { MX1 } \\
\text { 56_P } \\
\text { anel_ } \\
2\end{array}$ & & & UD C415 & 12 & 62,19 & $\begin{array}{c}\text { MODE I } \\
\text { Short beam }\end{array}$ \\
\hline
\end{tabular}




\begin{tabular}{|c|c|c|c|c|c|}
\hline \begin{tabular}{c|c} 
MX1 \\
56_P \\
anel_ \\
3
\end{tabular} & & UD C415 & 10 & 57 & Impact \\
\hline
\end{tabular}

\subsection{Mechanical Testing}

The three-point bending test selected for the panel specimens is following ASTM D790. The test specimens contain 8 layers of G0926 fabric. The dimensions of the cut specimens were $125 \mathrm{~mm}$ long, $12.51 \mathrm{~mm}$ wide and $3.05 \mathrm{~mm}$ thick. In the three-point method, the load (P) is exerted in the middle of the distance of the support points. The standard to be followed for the tensile test is ASTM D638. The tensile machine used exerts a maximum load of $100 \mathrm{kN}$ in ambient conditions. The specimens cut from the panel are in the form of "dog bones" and their dimensions are $170 \mathrm{~mm}$ long, $13 \mathrm{~mm}$ wide and $3 \mathrm{~mm}$ thick. The specimens for the impact test have a width of $10 \mathrm{~mm}$ and a thickness of $4 \mathrm{~mm}$. The length of all specimens submitted to the impact test is defined based on the standard and equals 80 $\mathrm{mm}$. The standard followed is ISO 180. The geometry and dimensions of the fracture toughness specimens are given Figure 1. The hatched areas represent the pre-crack $\left(\alpha_{0}\right)$; the initial delamination length, chosen to be equal to $50 \mathrm{~mm}$ following ASTM D5528 [3]. Two piano hinges aligned with the specimen axis and loading line were bonded to the precracked edge of the specimens with the use of two-part toughened epoxy adhesive. The specimens were left for $24 \mathrm{~h}$ at room temperature for the sufficient curing of adhesive. In aiding crack length measurements, thin vertical lines have been marked on the lateral sides of the specimens with a spacing of $5 \mathrm{~mm}$.

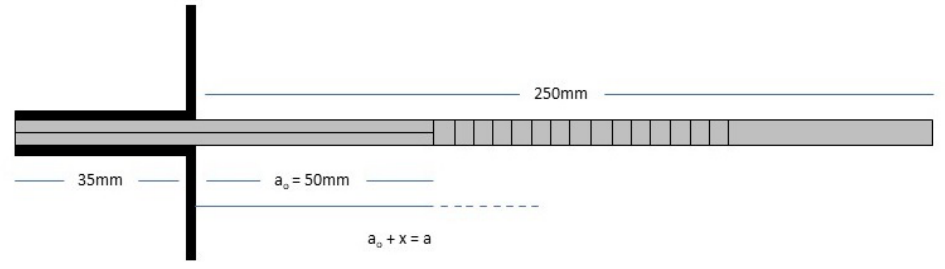

Figure 1. Fracture toughness specimens' dimensions

\section{Results and Discussion}

\subsection{Bending Test}

The 3-point bending test was performed on a total of 6 composite samples of threecomponent Araldite resin and another 6 containing MX156 resin with core-shell particles. All the above specimens were taken from a composite panel and cut to the desired dimensions by water cutting. The results for the two types of composites are listed below.

Table 2. 3-point bend test results

\begin{tabular}{|c|c|c|c|}
\hline Specimen type & $\begin{array}{c}\text { Flexural } \\
\text { Strength (MPa) }\end{array}$ & $\begin{array}{c}\text { Modulus } \\
\text { (GPa) }\end{array}$ & Strain (\%) \\
\hline Pristine & $768 \pm 19$ & $49.2 \pm 1$ & $1.84 \pm 0.06$ \\
\hline MX 156 & $662 \pm 10$ & $39.1 \pm 1.6$ & $2.32 \pm 0.16$ \\
\hline
\end{tabular}




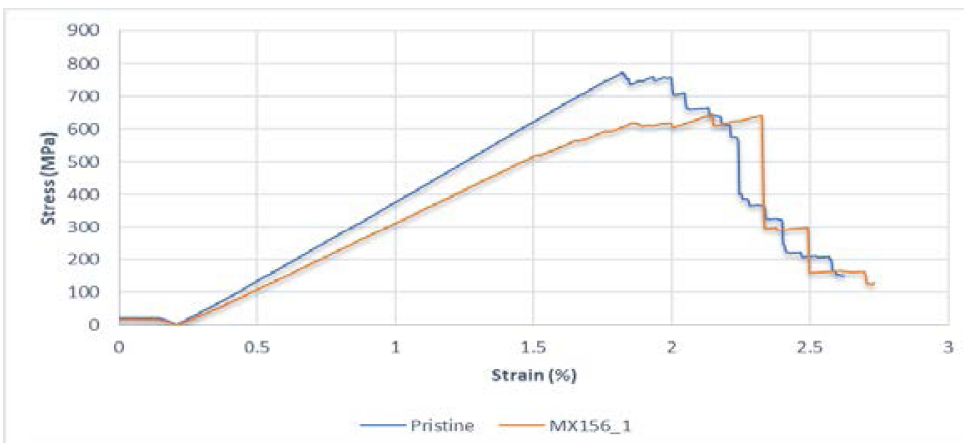

Figure 2. Stress-strain diagram for the two types of specimens in the bending test (specimens with Pristine resin in blue and specimens with MX156 in orange).

The above results are based on the average values obtained for the 6 samples that underwent the bending test of the two types of resins, in which the standard deviation has been added as shown.

The presence of core-shell elastomers causes a slight reduction in the strength of the specimens and their modulus of elasticity, compared to the reference. The $13.8 \%$ reduction in flexural strength is due to the discontinuities in the core of the elastomers that reduce the strength of the epoxy resin and therefore the composite. The small reduction in strength and elasticity shows us that the type of carbon fibre used has a very good affinity for the resin[10].

\subsection{Tensile Test}

As defined by the standard for the tensile test, the specimen to be tested is anchored to the grips of the tensile machine and charged with a uniaxially progressively increasing load, until its final break. The Young modulus is calculated from the slope of the stress-strain diagram in the elastic region. As in the bending test, in this case, the composites used are both pristine and MX156, all with G0926 8-layer fabric reinforcement. The results are summarized in the following table and diagrams.

Table 3. Tensile Test Results

\begin{tabular}{|c|c|c|c|} 
Specimen Type & Tensile Strength (MPa) & $\begin{array}{c}\text { Young Modulus } \\
\mathbf{( G P a )}\end{array}$ & Strain (\%) \\
\hline Pristine & $776 \pm 11$ & $61.8 \pm 1.3$ & 1.17 \\
\hline MX 156 & $679 \pm 16$ & $57.4 \pm 0.6$ & 1.16 \\
\hline
\end{tabular}

In the case of the tensile test, the presence of core-shell nanospheres reduces the strength compared to the reference specimens under the same conditions. 


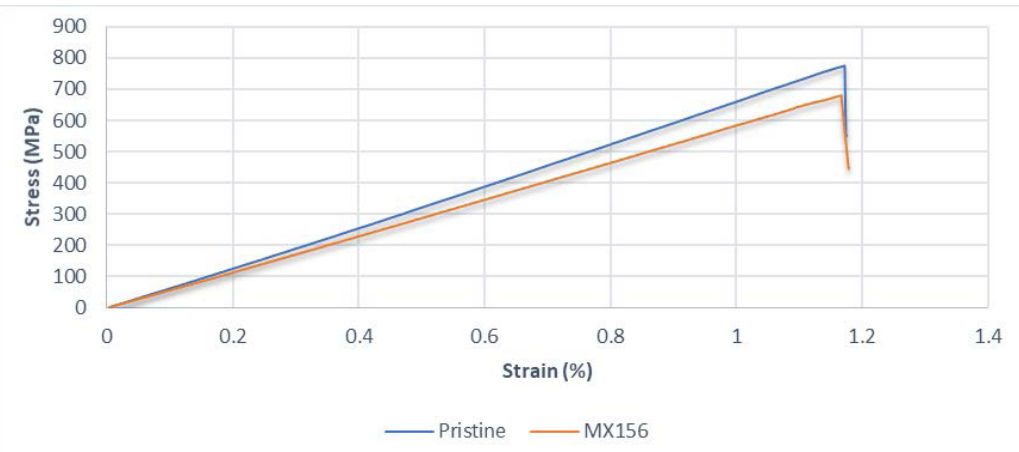

Figure 3. Stress-Strain diagram during the tensile test.

The figure above exhibits the stress-strain curves of the composite materials subjected to the tensile test. In addition to the strength, the young modulus of the samples having MX 156 resin, appears reduced compared to those that have as a matrix the reference Araldite resin. We conclude that the CFRPs containing CSR exhibit a reduction in the maximum tensile strength by $12.5 \%$. The decrease of the tensile properties is not relatively low, despite the incorporation of the shell core particles in them. The presence of discontinuities in the matrix of the composite materials results in a reduction in strength, as in the case of the bending test. It is concluded due to the small reduction that in CFRPs, the presence of carbon fibre fabric is a more important factor in determining the tensile properties than the presence of CSRs[11-12].

\subsection{Impact Test}

The test was performed at room temperature. In total, 4 types of fractures may occur in the specimens during the impact test. The complete break $(\mathrm{C})$, in which the specimen is divided into two or more parts. The incomplete fracture $(\mathrm{H})$, where the two parts of the resulting specimen are held in place by a thin, low-stiffness layer. The partial fracture $(\mathrm{P})$, in which the two parts of the specimen are held together by a thicker layer compared to the incomplete fracture. Finally, the non-break $(\mathrm{N})$, where there is no break and the sample simply bends. Practically, due to very little connection part in the case of incomplete breakage, it is considered the same case as the complete breakage. The table below lists the results obtained from the impact test for both types of specimens, while it is worth mentioning that all the specimens showed partial breakage.

Table 4. Impact test results

\begin{tabular}{|c|c|c|}
\hline Specimen type & Type of breakage & Impact Strength $\left.\mathbf{( K j} \mathbf{j} \mathbf{m}^{\mathbf{2}}\right)$ \\
\hline Pristine & P & $83.7 \pm 12.9$ \\
\hline MX156 & P & $125.4 \pm 29.3$ \\
\hline
\end{tabular}

The above results are based on the average of the samples that showed partial rupture. It is observed that the impact strength in the specimens containing the MX156 resin is $49.8 \%$ higher than in the specimens with Araldite. The structure of the epoxy composites is extremely cross-linked, resulting in this molecular structure leading to low resistance at the onset of crack propagation and therefore epoxy resins have low fracture toughness, thus reducing the strength of the composites. The use of CSR particles, which remain well dispersed in the epoxy matrix, improves the impact resistance of the specimens through several mechanisms.

Initially, the impact resistance of the composites is improved through the ability of CSR elastomers to absorb large amounts of energy and deform. Also, this increase is due to the cavity that exists within the core of the CSR through which an additional amount of energy 
is absorbed and therefore the strength of the composite during the impact test is increased. Finally, the particles dispersed in the resin act simultaneously during mechanical stress as crack terminators, to stop their growth inside the composite. For this reason, specimens containing MX156 resin with core-shell particles are more resistant to impact testing, even though they have the same type of breakage as pristine resin composites[13-14].

\subsection{Fracture Toughness Test}

This test is applied to composite materials, to calculate the rate of energy release at the opening of the specimen, as a function of the length of the developing crack. For this purpose and based on the standard followed, a longitudinal load is applied to the specimens which are achieved by adding hinges, to make a connection to the grips of the machine.

The diagram $\mathrm{G}_{\mathrm{I}}-\alpha$ is made after the calculation of the energy for specific values of the detachment length, which start from $50 \mathrm{~mm}$ and increase by 5 .

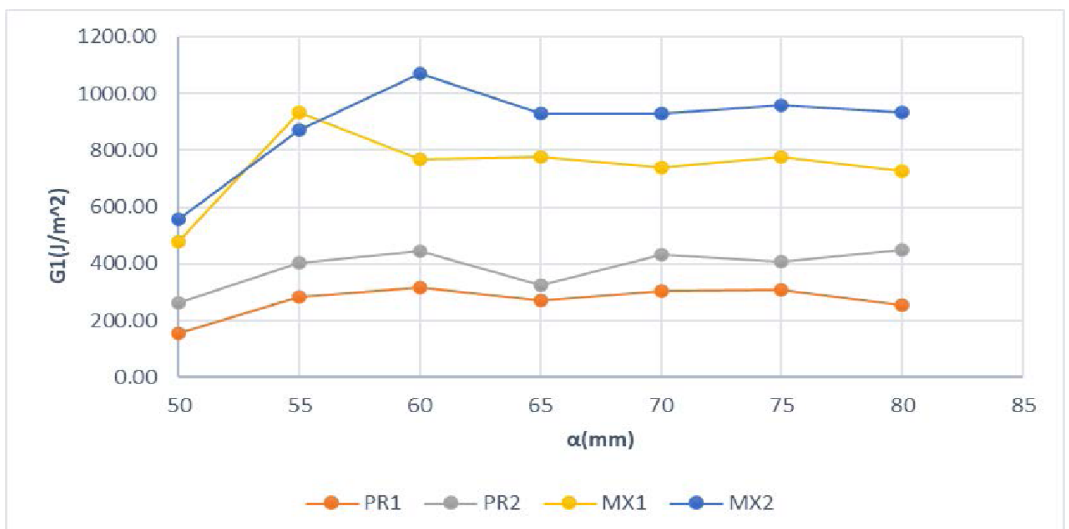

Figure 4. Diagram of the progress in $\mathrm{G}_{\mathrm{I}}$ energy as a function of crack propagation length in pristine specimens and specimens with CSR

As can be seen from the above diagram, the energy absorbed by the specimens during the fracture toughness test is increased by the presence of CSR, as their structure affects the mechanisms involved in the process of breaking the composite. More specifically, since these elastomers have a well-defined structure, the specimens containing MX 156 resin have a two-phase structure. Comparing the energies of the two types of specimens, we observe that the specimens containing the shell-core elastomers absorb greater amounts of energy during the propagation of the crack than those with the reference resin. This is due to the ability of CSRs to act as energy absorbers. The cavities formed in the core of the elastic phase (CSR) are responsible for the fluctuations of the absorbed energy $\left(\mathrm{G}_{\mathrm{I}}\right)$, in contrast to the fibre-matrix specimens, which do not show these fluctuations and the only resistance to the propagation of cracks during the test, is that of the fibre bridging zone. The tendency of core-shell elastomers to absorb vibrations when the composite is mechanically stressed and to act as crack terminators is also evident from the fluctuations in the curves, through the energy absorbed as compensation to crack propagation[13-14].

\subsection{Short Beam Test}

Short-beam test was performed on six samples of each type and the results are summarized on average in the following table. 
Table 5. Short-beam test Results

\begin{tabular}{c|c|} 
Specimen Type & $\tau_{\mathrm{b}}(\mathrm{MPa})$ \\
\hline Pristine & $59.6 \pm 4.2$ \\
\hline MX156 & $53.7 \pm 1.9$ \\
\hline
\end{tabular}

Shear strength is slightly reduced by the presence of core-shell rubbers, compared to specimens containing the reference resin. On average, specimens containing MX 156 resin have a $9.9 \%$ lower strength than reference.

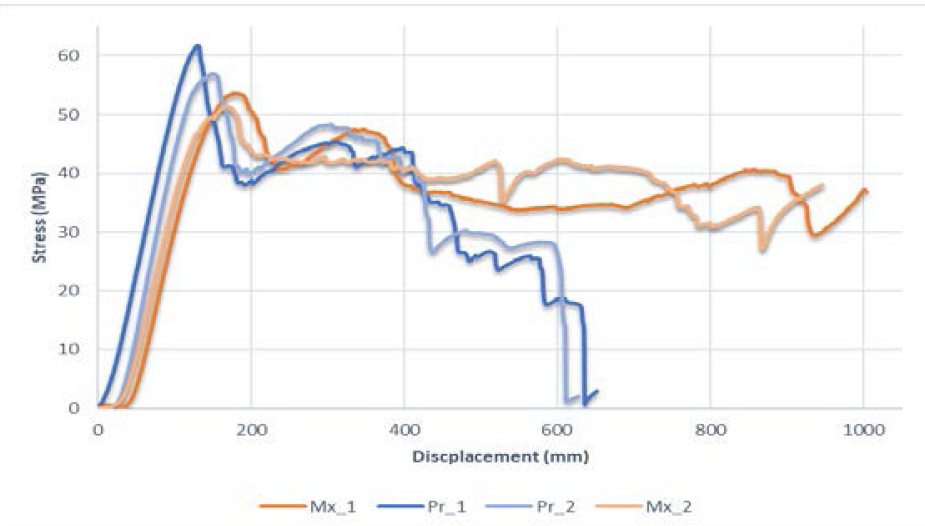

Figure 5. Schematic representation of shear strength as a function of displacement.

The diagram above shows the shear strength of two specimens with the pristine resin and two with the MX 156 resin. Despite the slight decrease in strength, it is observed that in the two specimens containing the MX resin, after some displacement value, there is relative stability in the strength values, which is followed by a plateau, in contrast to the corresponding values in the specimens, consisting reference resin. This is due to the ability of the core-shell particles to terminate prematurely some of the cracks that develop in the composites (crack terminators) and thus extend the life of the composites.

\section{Conclusions}

The purpose of the present study was to fabricate composite materials containing dispersed core-shell rubbers. New composites were compared with references, through a variety of mechanical tests. The mechanical tests submitted by both types of tests are the three-point bending, tensile, shear, impact and fracture toughness test, from which the following conclusions are drawn. The presence of CSRs in the composite reduces the modulus of elasticity and therefore the flexural and tensile properties. This is expected since the discontinuities in the core of the elastomers reduce the strength of the epoxy resin and therefore the composite. The impact properties are increased by $50 \%$, while in the fracture toughness test, specimens with CSR demanded 4 times greater energy than reference specimens. This increase in strength is due to their ability to deform when absorbing energy and thus increase the impact resistance of the composite specimen. Also, the cavity formed in the elastomer core absorbs energy during impact and increases the strength of the specimen. Finally, the scattered CSRs act uniformly to stop the development of cracks during the impact test. Finally, from short beam test the ability of CSR to prolong the service life of CFRPs is observed. 
This work was supported by the EU H2020 Project "SMARTFAN - Smart by Design and Intelligent by Architecture for turbine blade fan and structural components systems" under Grant Agreement no. 760779.

\section{References}

1. Ming Lu, Bo He, Liansheng Wang, Wen Ge, Qiuyu Lu, Yakang Liu, Liqun Zhang, Preparation of polystyrene-polyisoprene core-shell nanoparticles for reinforcement of elastomers, Composites Part B: Engineering, Volume 43, Issue 1,2012, Pages 50-56

2. Atsunori Tajima, Takeshi Higuchi, Hiroshi Yabu, Masatsugu Shimomura, Hemispherical polymer nano-particles of polyisoprene-poly(methyl methacrylate) blend with core-shell structure, Colloids and Surfaces A: Physicochemical and Engineering Aspects, Volumes 313-314, 2008, Pages 332-334

3. Bunthita Suppaibulsuk, Garry L Rempel, Pattarapan Prasassarakich, Synthesis of styrene-gpolyisoprene nanoparticles by emulsion polymerization and its effect on properties of polyisoprene composites, Polymer Advanced Technologies, Volume 23, 2012, Pages 14771483

4. J. Chouytan, S. Beraheng, E. Kalkornsurapranee, C. M. Fellows \& W. Kaewsakul, Synthesis of Polyisoprene via Miniemulsion Polymerisation: Effect on Thermal Behaviour, Colloidal Properties and Stereochemistry, Journal of Rubber Research Volume 21, 2018, Pages 236255

5. Myriam R. Lorenz, Maria-Verena Kohnle, Martin Dass, Paul Walther, Anita Hocherl, Ulrich Ziener, Katharina Landfester, Volker Mailander, Synthesis of Fluorescent Polyisoprene Nanoparticles and their Uptake into Various Cells, Macromolecular Bioscience, Volume 8, 2008, Pages 711-727

6. F. Cataldo, O. Ursini, E. Lilla, Radiation induced polymerization of isoprene: A spectroscopic study, Journal of Radioanalytical and Nuclear Chemistry, Volume 275, 2008, Pages 9-16

7. Y. Apolinar, L. F. Ramos, H. Saade, R. Diaz de Leon, and R. G. Lopez, Polyisoprene Nanoparticles Prepared by Polymerization in Microemulsion, Journal of Nanomaterials, 2010, Pages 1-6

8. G. Giannakopoulos, K. Masania, A. C. Taylor, Toughening of epoxy using core-shell particles, Journal of Material Science, Volume 46, 2011, Pages 327-338

9. D. Carolan, A. Ivankovic, A. J. Kinloch, S. Sprenger, and A. C. Taylor, Toughened carbon fibre-reinforced polymer composites with nanoparticle-modified epoxy matrices, Journal of Material Science, Volume 52, 2017, Pages 1767-1788

10. J. Chen, A.J. Kinloch, S. Sprenger, A.C. Taylor, The mechanical properties and toughening mechanisms of an epoxy polymer modified with polysiloxane-based core-shell particles, Polymer, Volume 54, 2013, Pages 4276-4289

11. Shuiping Li, Qisheng Wu, Huajun Zhu, Qing Lin, Chengshuang Wang, Impact Resistance Enhancement by Adding Core-Shell Particle to Epoxy Resin Modified with Hyperbranched Polymer, Polymers, Volume 9, Pages 1-12

12. A. Keller, H.M. Chong, A.C. Taylor, C. Dransfeld, K. Masania, Core-shell rubber nanoparticle reinforcement and processing of high toughness fast-curing epoxy composites, Composites Science and Technology, Volume 147, 2017, Pages 78-88

13. Dong Quan, Alojz Ivankovic, Effect of coreeshell rubber (CSR) nano-particles on mechanical properties and fracture toughness of an epoxy polymer, Polymer, 2015, Pages 16-28

14. Hyeongcheol Park, Hana Jung, Jaesang Yu, Min Park and Seong Yun Kim, Carbon fiberreinforced plastics based on epoxy resin toughened with core shell rubber impact modifiers, Polymers, Volume 15, 2015, Pages 369-375 